\title{
$5-2011$
}

\section{Beyond CiSE and Back to the Future}

George K. Thiruvathukal

Loyola University Chicago, gkt@cs.luc.edu

Follow this and additional works at: https://ecommons.luc.edu/cs_facpubs

Part of the Computer Sciences Commons

\section{Recommended Citation}

George K. Thiruvathukal, "Beyond CiSE and Back to the Future," Computing in Science and Engineering, vol. 13, no. 3, pp. 4-5, May/June 2011, doi:10.1109/MCSE.2011.44

This Article is brought to you for free and open access by the Faculty Publications and Other Works by Department at Loyola eCommons. It has been accepted for inclusion in Computer Science: Faculty Publications and Other Works by an authorized administrator of Loyola eCommons. For more information, please contact ecommons@luc.edu.

\section{(c) (1) $\odot \Theta$}

This work is licensed under a Creative Commons Attribution-Noncommercial-No Derivative Works 3.0 License. Copyright @ 2011 George K. Thiruvathukal 


\title{
F R O M \\ THE E DITOR S
}

\section{Beyond Cise AND BaCk to the Future}

\author{
By George K. Thiruvathukal
}

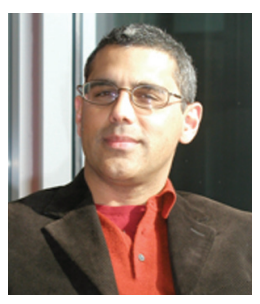

\author{
DCENTLY, I HAD THE PLEASURE OF ORGANIZING A SPECIAL ISSUE FOR \\ COMPUTING NOW (CN), THE IEEE COMPUTER SOCIETY'S PUBLICATIONS
}

\author{
PORTAL SITE (WWW.COMPUTER.ORG/COMPUTINGNOW). AS I NOTED IN A
}

PREVIOUS ARTICLE, ${ }^{1}$ I'VE BEEN ACTIVE IN HELPING TO LEAD AND SHAPE

CN's direction as the CiSE liaison and as an associate editor for both CiSE and CN. When CiSE's then-EIC Norman Chonacky asked me to participate in $\mathrm{CN}$, it was to apply my experience in emerging technologies to help the IEEE Computer Society. Doing so has been a rewarding experience, to say the least.

But something felt amiss: Since joining CN, I've not been able to promote CiSE because many challenges have kept us-the CN volunteers and staff-busy. It's hard to believe that we're nearing the portal's three-year anniversary, which itself is something to celebrate considering that $\mathrm{CN}$ was at least the fourth effort by the Computer Society to do more with member engagement, find alternate models for content delivery, and so on. So, when I finally got an opportunity in January to do what I enjoy doing mostcoming up with good ideas for theme issues and writing and selecting articles for them-I was pretty excited.

\section{A Novel Approach to Architectures}

I'd been working on all sorts of things for $\mathrm{CN}$, including exploring the use of e-books, mobile applications (the CN Android app was created by one of my students, with my mentorship), blogging, and so on. For February's CN (www.computer.org/portal/web/computingnow/archive/ february2011), I decided to create a special issue based on novel architectures, similar to the CiSE theme issue I coedited with Steve Gottlieb and Volodymyr Kindradenko in 2008. ${ }^{2}$ Since then, the topic has grown even hotter.

Having already organized the guest editor introduction and knowing that we'd already accepted several good peerreviewed articles for publication, I wanted to try something different. Luckily for me, CN's creative staff (Steve Woods, Brooke Miner, and Brandi Ortega) had also been asking me to consider incorporating some additional content into my theme. Being ever the experimentalist, I decided to put together a how-to video about how you can build your own computer at home to develop general-purpose computation on graphics processing units (GPGPU). After all, I've been building my own computers for years in Loyola University's Emerging Technologies Laboratory and was actively working on building small-form-factor computers for various systems and embedded projects that I do in my laboratory at home. Then, I realized that I don't need to stop at a discussion about the computer. I could also describe how to get started with GPGPU development. This sort of nonlinear presentation is something that wouldn't work in print alone. Then again, I was glad that I had something in print that served as a foundation for an interesting online theme.

\section{Outcomes and Opportunities}

To my delight, the theme was a resounding success, at least based on our Web analytics. We apparently broke CN's all-time traffic record. More importantly, there was a substantial number of click-throughs to CN's monthly newsletter. Needless to say, this was incredibly exciting for me and made me want to do it again. A key lesson learned is that augmenting a theme issue intended primarily "for geeks only" with accessible content (a simplified narrative and a how-to video) seemed to be exactly what many readers wanted.

In any event, as I was installing the Nvidia driver, SDK, and code samples on my home-brewed computer, I was delighted to see a plethora of examples that CiSE readers would actually care about. Among these are the $n$-body simulation, a smoke particle simulation, and numerous other numerical algorithms and scientific simulations that don't always have a visual component, but are nevertheless exciting to geeks like me and likely to most CiSE readers.

So, as the video shows (see www.computer.org/portal/ web/computingnow/archive/february2011), there I was in my home office running a large $n$-body simulation on a small-form-factor computer. Being an early mid-career 


\section{Cise Welcomes New Board MEMBER}

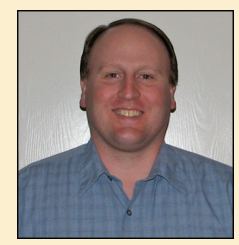

cott Hemmert is a senior member
of the technical staff at Sandia National Laboratories, where he leads the advanced supercomputer interconnect research. He's also a member of the joint Sandia/Los Alamos National

Laboratory Alliance for Computing at Extreme Scale (ACES) design team, where he serves as lead for interconnect architectures. Hemmert is actively involved in charting the US Department of Energy's path to exascale computing, currently serving as group lead over hardware architectures for the DOE/National Nuclear Security Administration exascale planning. His research interests include highperformance computing architectures, with a particular focus on high-speed interconnects. Hemmert has a PhD in electrical engineering from Brigham Young University. Contact him at kshemme@sandia.gov. computer scientist, I still remember my first visits to Argonne National Laboratory in the 1980s where there was a Cray vector machine whose combined processing power and memory would be no match for the latest generation of GPGPU servers. It blew my mind to think that these computations-which absolutely required supercomputers in the old days-could now be done in the comfort and safety of my home. True, we still need large-scale computation for the largest of problems. But it's awe-inspiring to think what we now can do before we run our code on a supercomputer.

once had a conversation with a computational scientist who said that the days of "amateur" computational science are dead. Perhaps. But perhaps the discussion has become a bit more refined. I still like to tinker and explore the possibilities, much like I did in preparing CN's theme issue. Given the rapid pace at which technology continues to evolve, we must continue doing intelligent experiments and evaluating a technology's effectiveness before we deploy it on a grand scale.
As my videos for CN's special issue exemplify, the opportunities to share and discuss such experiments are broader and more exciting than ever. I hope you'll check out my theme issue in $\mathrm{CN}$, if only to see what a successful foray into value-added content-beyond our already excellent articles-might look like for CiSE. If you'd like to discuss ideas on these topics, feel free to contact me through my Web page at www.thiruvathukal.com.

\section{References}

1. G.K. Thiruvathukal, "Introducing Computing Now," Computing in Science \& Eng., vol. 11, no. 4, 2009, pp. 8-10.

2. V. Kindratenko, G.K. Thiruvathukal, and S. Gottlieb, "HighPerformance Computing Applications on Novel Architectures," Computing in Science \& Eng., vol. 10, no. 6, 2008, pp. 13-15.

George K. Thiruvathukal is a professor of computer science and codirector of the Center for Textual Studies/Digital Humanities at Loyola University Chicago. He is an associate editor in chief of CiSE and an associate editor of Computing Now. Contact him at gkt@ cs.luc.edu or visit his page at http://home.thiruvathukal.com.

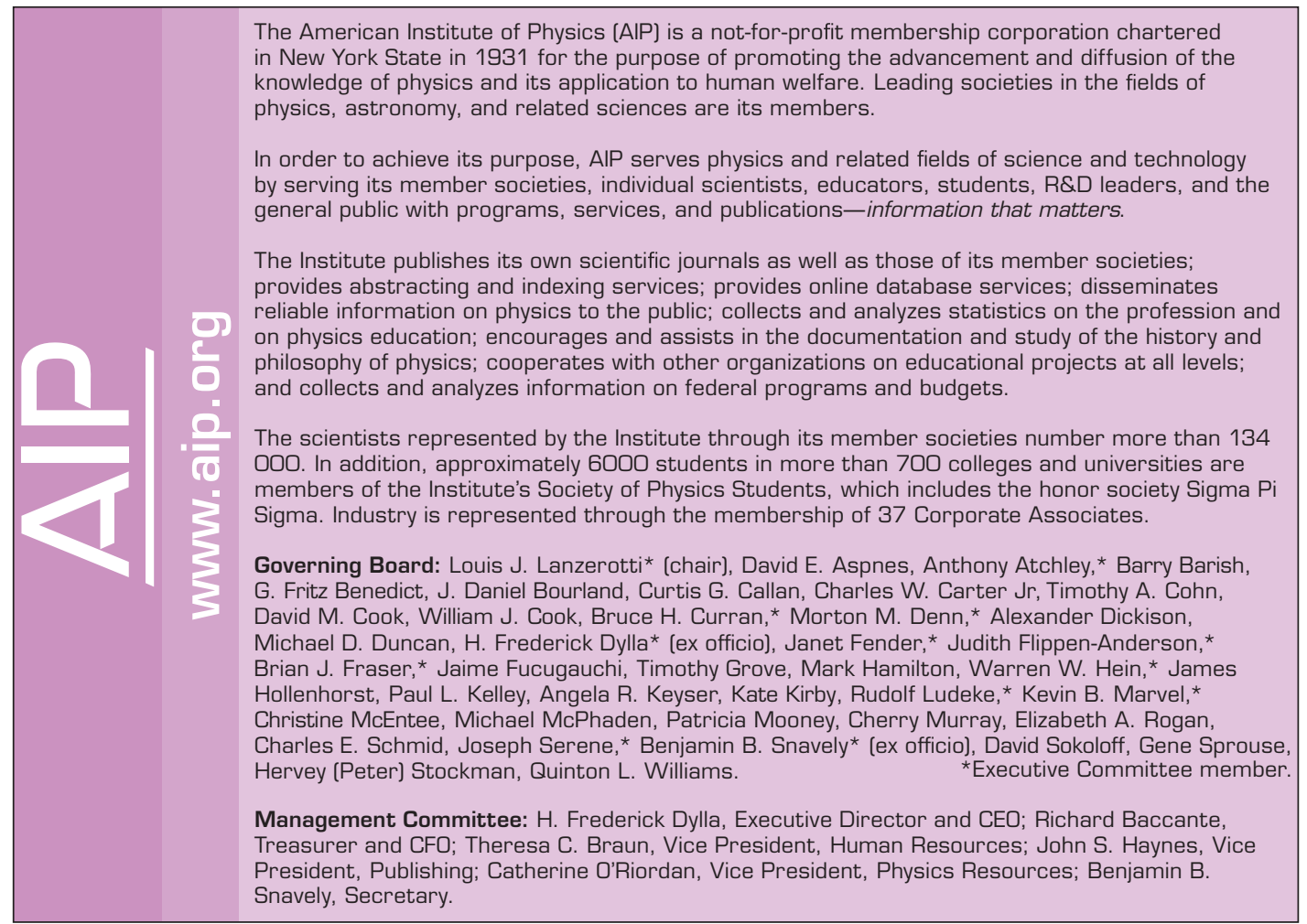

